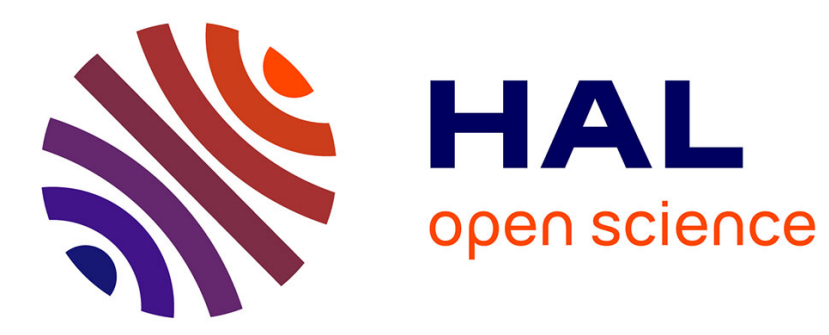

\title{
Impact of the in situ SiN Thickness on Low-Frequency Noise in MOVPE InAlGaN/GaN HEMTs
}

M. Rzin, B. Guillet, Laurence Méchin, P. Gamarra, C. Lacam, F Medjdoub, J.-M. Routoure

\section{- To cite this version:}

M. Rzin, B. Guillet, Laurence Méchin, P. Gamarra, C. Lacam, et al.. Impact of the in situ SiN Thickness on Low-Frequency Noise in MOVPE InAlGaN/GaN HEMTs. IEEE Transactions on Electron Devices, 2019, 66 (12), pp.5080-5083. 10.1109/TED.2019.2945296 . hal-02382779

\section{HAL Id: hal-02382779}

https://hal-normandie-univ.archives-ouvertes.fr/hal-02382779

Submitted on 7 Jun 2020

HAL is a multi-disciplinary open access archive for the deposit and dissemination of scientific research documents, whether they are published or not. The documents may come from teaching and research institutions in France or abroad, or from public or private research centers.
L'archive ouverte pluridisciplinaire HAL, est destinée au dépôt et à la diffusion de documents scientifiques de niveau recherche, publiés ou non, émanant des établissements d'enseignement et de recherche français ou étrangers, des laboratoires publics ou privés. 


\title{
Impact of the in situ SiN thickness on low frequency noise in MOVPE InAlGaN/GaN HEMTs
}

\author{
M. Rzin, B. Guillet, L. Méchin, P. Gamarra, C. Lacam, F. Medjdoub and J-M. Routoure
}

\begin{abstract}
This paper reports on sub-10 nm quaternary barrier InAIGaN/GaN High Electron Mobility Transistors (HEMTs) grown by Metal-Organic-Vapor-Phase-Epitaxy (MOVPE) with an in situ SiN passivation layer, and ultra-short gate length of $200 \mathrm{~nm}$. Two batches of HEMTs with two SiN thicknesses $\left(t_{\text {SiN }}\right)$ of 14 and $22 \mathrm{~nm}$ are studied. Low Frequency Noise (LFN) measurements of the drain current have been carried out in the linear regime and showed that the in situ $\mathrm{SiN}$ thickness has no impact on the noise performance. $S_{I D} / I_{D}{ }^{2}$ in the linear regime dependence over the gate overdrive shows that the channel noise is located under the gate and that the noise is not impacted by the thickness of the in situ SiN layer.
\end{abstract}

Index Terms-InAlGaN/GaN, in situ SiN passivation, low frequency noise, HEMT

\section{INTRODUCTION}

$\mathrm{U}$ LTRA-THIN quaternary barrier InAlGaN/GaN High Electron Mobility Transistors (HEMTs) hold a tremendous potential for microwave and millimeter-wave applications, thanks to their outstanding 2-DEG properties that allowed to achieve state of the art electron mobility of $1800 \mathrm{~cm}^{2} \cdot \mathrm{V}^{-1} \cdot \mathrm{s}^{-1}$ and sheet carrier density of $1.9 \cdot 10^{13} \mathrm{~cm}^{-2}$ at room temperature [1]. This is owing to the use of Al-rich InAlGaN layers having an important effect to enhance the carrier density and achieve high frequency performance due to the increase of the spontaneous polarization [2]-[6].

One of the critical parameters limiting dynamic and power performance as well as the electrical reliability of $\mathrm{GaN}$ based HEMTs is the gate leakage current that might increase under high electric field [7]-[9]. The parasitic effects leading to current collapse and gate leakage current increase have been reduced by using deposited $\mathrm{SiN}$ passivation [10]-[12].

This work was supported by National Research Agency under contract $\mathrm{N}^{\circ}$ ANR-14-CE26-0022 (LHOM).

M. Rzin was with Normandie Univ., UNICAEN, ENSICAEN, CNRS, GREYC, 14000 Caen, France. He is now with DEI, University of Padova, Italy (e-mail: mehdi.rzin@ensicaen.fr).

B. Guillet, L. Méchin and J.-M. Routoure are with Normandie Univ, UNICAEN, ENSICAEN, CNRS, GREYC, 14000 Caen, France (e-mail: bruno.guillet@unicaen.fr;_ laurence.mechin@ensicaen.fr, jeanmarc.routoure@unicaen.fr).

P. Gamarra and C. Lacam are with III-V Lab, Thales Research and Technology, 91767 Palaiseau, France (e-mail: piero.gamarra@3-5lab.fr, cedric.lacam@3-5lab.fr).

F. Medjdoub is with IEMN, UMR8520, 59650 Villeneuve d'Ascq, France (e-mail: farid.medjdoub@iemn.univ-lille1.fr).
However, the leakage current remains a serious issue when ultra-thin barrier layers are used. In order to reduce the leakage current under the gate and/or in the gate-drain access region, the deposition of an in situ SiN passivation layer on top of the quaternary barrier in the Metal-Organic-VaporPhase-Epitaxy (MOVPE) reactor has been proposed and successfully applied.

The passivation layer deposited in the same growth run as the III-N heterostructure reduces the relaxation, cracking and surface roughness of the barrier layer [13]. Moreover, the low growth rate and the relative high growth temperature of in situ SiN layer reduce the formation of surface states and improve the performance of the 2DEG properties.

The thickness of in situ $\mathrm{SiN}$ dielectric gate has a significant impact on the leakage current and may affect the drain current. Thick SiN cap increases the distance between the channel and the surface, thus reducing the surface state effects. On the other hand, much larger $\mathrm{SiN}$ cap makes the definition of ultra-short gate footprints more challenging.

Low frequency noise (LFN) measurements can be used to investigate the material/device quality, to identify material defects and trapping effects, and to investigate the reliability of GaN based HEMTs [14]-[18]. In addition to significant reduction of the gate leakage current and the increase of the sheet charge density, the in situ SiN passivation layer can also potentially improve the low frequency device noise performance [19]-[23].

In this letter, we report on low frequency noise measurements performed on InAlGaN/GaN HEMTs with different MOVPE in situ SiN passivation thicknesses.

\section{EXPERIMENTAL DETAILS}

The SiN/InAlGaN/GaN HEMT structures were grown in an Aixtron Close Coupled Showerhead (CCS) MOVPE reactor on $4 \mathrm{H}-\mathrm{SiC}$ semi-insulating substrates.

The growth details were published in Ref. [24]. First SiC substrate surfaces were prepared in $\mathrm{H}_{2}$ and the growth was initiated with an AlN nucleation layer (100 nm thick) at high temperature. A $1.6 \mu \mathrm{m}$ thick highly resistive carbon doped GaN buffer layer, a $150 \mathrm{~nm}$ thick non-intentionally doped GaN channel, an AlN interlayer with a nominal thickness of $1.2 \mathrm{~nm}$ and a $6 \mathrm{~nm}$ thick InAlGaN barrier layer were subsequently deposited. It was checked by STEM-EDS (Scanning Transmission Electron Microscopy - EnergyDispersive Spectrometry) and $\mu$-Auger analyses that the 
quaternary barrier showed Ga content of about $8-10 \%$ and In content ranging from $10 \%$ to $12 \%$. At last, the SiN passivation layer (14 $\mathrm{nm}$ or $22 \mathrm{~nm}$, noted $\mathrm{t}_{\mathrm{SiN}}$ ) was deposited on top of these heterostructures without growth interruption. Scanning Probe Microscopy (SPM) in conductive mode shows that the targeted thicknesses for the passivation layers are sufficiently thick to act as insulating layers. Device processing was performed as follows: ohmic contacts were formed directly on top of the InAlGaN barrier layer by etching the in situ $\mathrm{Si}_{\mathrm{x}} \mathrm{N}_{\mathrm{y}}$ layer using a Fluorine-based plasma. A Ti/A1/Ni/Au metal stack was used, followed by rapid thermal annealing at 875 ${ }^{\circ} \mathrm{C}$. Device isolation was achieved by nitrogen implantation. Ohmic contact resistances extracted from linear transmission line model (TLM) structures were $0.3 \Omega$. mm on average. A $\mathrm{Ni} / \mathrm{Au} \mathrm{T}$-gate of $200 \mathrm{~nm}\left(\mathrm{~L}_{\mathrm{G}}\right)$ was defined by e-beam lithography. Finally, a $200 \mathrm{~nm}$ thick $\mathrm{SiN}$ layer has been deposited as passivation.

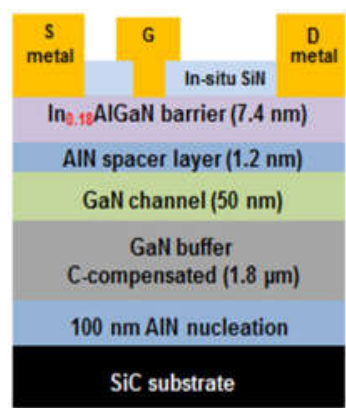

(a)

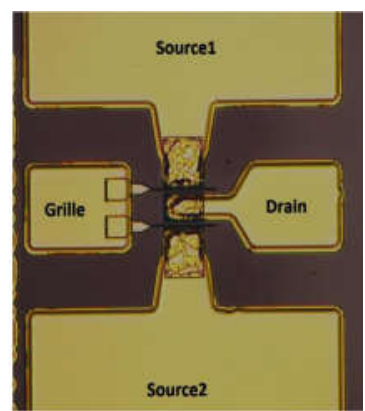

(b)
Fig. 1. (a) Schematic cross-section view and (b) optical microscope image of SixNy/InAlGaN/AlN/GaN HEMT with 2 finger gates.

In this work, the studied devices have a $\mathrm{Ni} / \mathrm{Au} \mathrm{T}$-gate of $200 \mathrm{~nm}$ length $\left(\mathrm{L}_{\mathrm{G}}\right)$ with two finger gates of width $\mathrm{W}_{\mathrm{G}}=$ $25 \mu \mathrm{m}$. and 3 different gate drain region spacings $\mathrm{L}_{\mathrm{GD}}(1,2$ and $3 \mu \mathrm{m})$. The schematic cross-section view and an optical microscope image of the HEMT heterostructure are displayed in figure 1.

\section{RESULTS AND DISCUSSION}

Typical $\mathrm{I}_{\mathrm{D}}-\mathrm{V}_{\mathrm{GS}}$ and $\mathrm{g}_{\mathrm{m}}-\mathrm{V}_{\mathrm{GS}}$ characteristics at $\mathrm{V}_{\mathrm{DS}}=200 \mathrm{mV}$ in the linear regime of two representative InAlGaN/GaN HEMTs (A) with $\mathrm{t}_{\mathrm{SiN}}=14 \mathrm{~nm}$ and $\mathrm{L}_{\mathrm{GD}}=1,2$ and $3 \mu \mathrm{m}$ are shown in Fig.2. The threshold voltage is around $-1.6 \mathrm{~V}$. These devices have an electron mobility of $1792 \mathrm{~cm}^{2} \cdot \mathrm{V}^{-1} \cdot \mathrm{s}^{-1}$ and sheet carrier density of $1.64 \cdot 10^{13} \mathrm{~cm}^{-2}$, resulting in a sheet resistance of $212 \Omega / \square$. Fig. 3 shows $I_{D}-V_{G S}$ and $g_{m}-V_{G S}$ characteristics of two representative InAlGaN/GaN HEMTs (B) with $\mathrm{t}_{\mathrm{SiN}}=22 \mathrm{~nm}$ and $\mathrm{L}_{\mathrm{GD}}=2$ and $3 \mu \mathrm{m}$. The threshold voltage is around $-2.2 \mathrm{~V}$. These devices have an electron mobility of $1772 \mathrm{~cm}^{2} \cdot \mathrm{V}^{-1} \cdot \mathrm{s}^{-1}$ and sheet carrier density of $1.60 \cdot 10^{13} \mathrm{~cm}^{-2}$, resulting in a sheet resistance of $220 \Omega / \square$.

The gate and drain subthreshold leakage currents are between 1 and $10 \mu \mathrm{A} / \mathrm{mm}$ at $\mathrm{V}_{\mathrm{GS}}=-5 \mathrm{~V}$ and $\mathrm{V}_{\mathrm{DS}}=10 \mathrm{~V}$, typical of the Schottky contact on GaN based HEMTs. The main difference between A and B HEMTs is the negative shift of the threshold voltage when increasing the SiN thickness from 14 to $22 \mathrm{~nm}$.
The power spectral density (PSD) of the drain current $\mathrm{S}_{\mathrm{ID}}$ was measured in the linear regime at $\mathrm{V}_{\mathrm{DS}}=200 \mathrm{mV}$ to identify the dominant noise sources in the channel with these two in situ SiN passivation thicknesses. Noise measurements were carried out on devices under stationary conditions and were reproducible. At low frequency, $\mathrm{S}_{\mathrm{ID}}$ varies as $1 / \mathrm{f}$ type spectra (in the $1 \mathrm{~Hz}$ to $1 \mathrm{kHz}$ frequency range) and no generationrecombination noise components were observed.

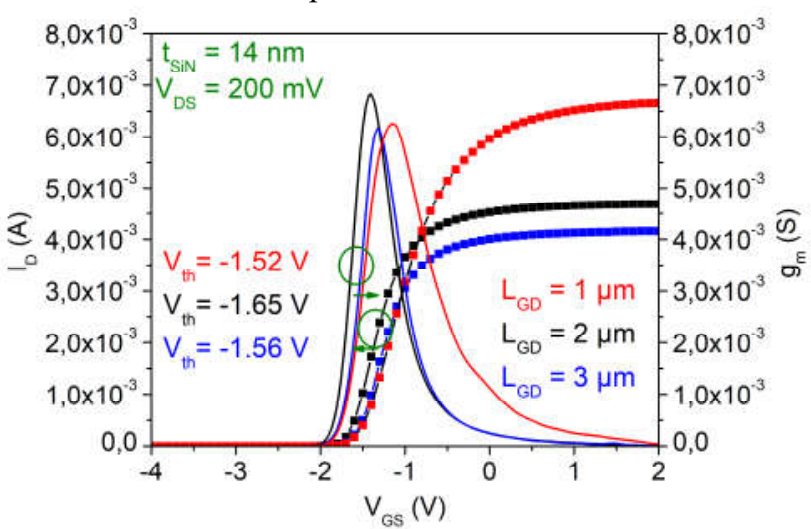

Fig. 2. $\mathrm{I}_{\mathrm{D}}-\mathrm{V}_{\mathrm{GS}}$ and $\mathrm{g}_{\mathrm{m}}-\mathrm{V}_{\mathrm{GS}}$ of InAlGaN/GaN MIS HEMTs with $\mathrm{t}_{\mathrm{SiN}}=14 \mathrm{~nm}$ and $\mathrm{L}_{\mathrm{GD}}=1,2$ and $3 \mu \mathrm{m}$ at $\mathrm{V}_{\mathrm{DS}}=200 \mathrm{mV}$.

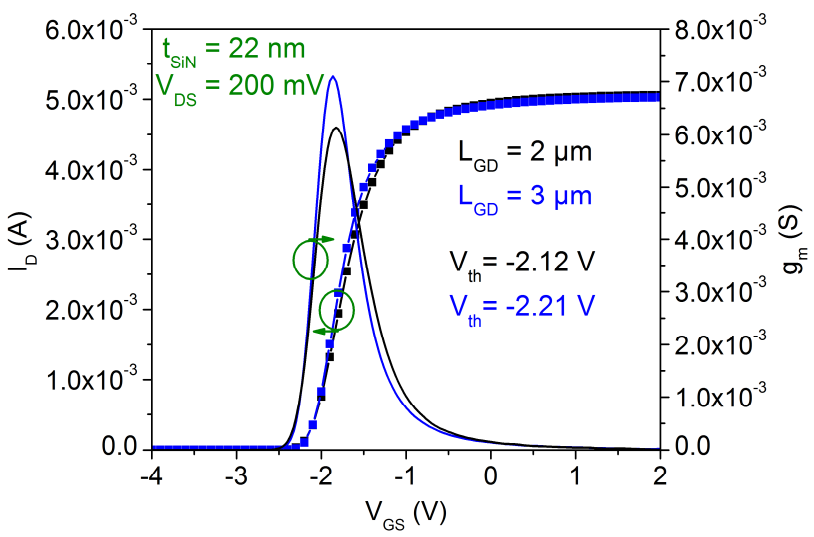

Fig. 3. $I_{D}-V_{G S}$ and $g_{m}-V_{G S}$ of InAlGaN/GaN MIS HEMTs with $t_{S i N}=22 \mathrm{~nm}$ and $\mathrm{L}_{\mathrm{GD}}=2$ and $3 \mu \mathrm{m}$ at $\mathrm{V}_{\mathrm{DS}}=200 \mathrm{mV}$.

The experimental points representing $\mathrm{S}_{\mathrm{ID}} / \mathrm{I}_{\mathrm{D}}{ }^{2}$ versus gate overdrive voltage $\left(\mathrm{V}_{\mathrm{GS}}-\mathrm{V}_{\mathrm{TH}}\right)$, in the linear regime $\left(\mathrm{V}_{\mathrm{DS}}=200\right.$ $\mathrm{mV}$ ), of $\mathrm{InAlGaN} / \mathrm{GaN}$ HEMTs with $\mathrm{L}_{\mathrm{GD}}=1,2$ and $3 \mu \mathrm{m}$ are shown in Fig.4. There is no significant impact of $\mathrm{SiN}$ thickness on the noise performance. $\mathrm{S}_{\mathrm{ID}} / \mathrm{I}_{\mathrm{D}}{ }^{2}$ decreases with the gate overdrive as $\left(\mathrm{V}_{\mathrm{GS}}-\mathrm{V}_{\mathrm{TH}}\right)^{-3}$. Similar $\mathrm{S}_{\mathrm{ID}} / \mathrm{I}_{\mathrm{D}}{ }^{2}$ dependence over $\mathrm{V}_{\mathrm{GS}}-\mathrm{V}_{\mathrm{TH}}$ indicating the dominant channel noise is located under the gate, as reported in previous works on GaAs MODFETs [25] and AlGaN/GaN HEMTs [26]. In agreement with these results, it can be pointed out that the current collapse level within these devices as assessed by pulsed measurements has been found to be similar regardless of the SiN cap layer thickness. 


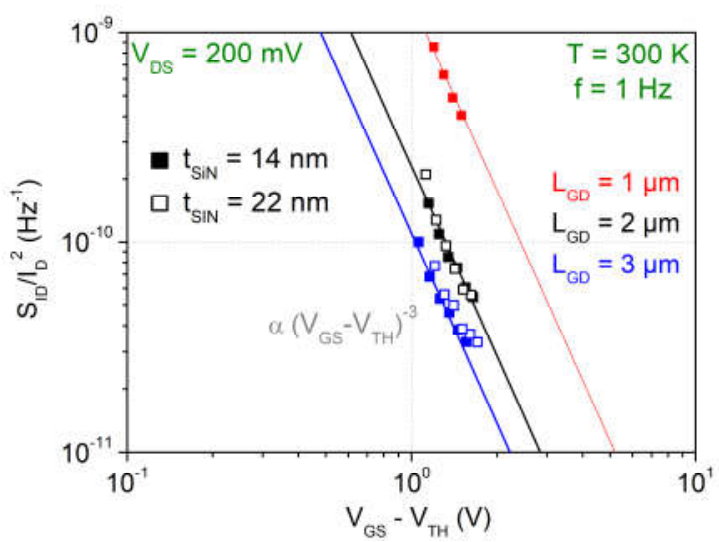

Fig. 4. Dependence of the relative PSD of the drain current $\mathrm{S}_{\mathrm{ID}} / \mathrm{I}_{\mathrm{D}}{ }^{2}$ on the gate overdrive $\left(\mathrm{V}_{\mathrm{GS}}-\mathrm{V}_{\mathrm{TH}}\right)$ at $\mathrm{f}=1 \mathrm{~Hz}, \mathrm{~V}_{\mathrm{DS}}=200 \mathrm{mV}$ and $\mathrm{T}=300 \mathrm{~K}$.

We previously analyzed $\mathrm{S}_{\mathrm{ID}} / \mathrm{I}_{\mathrm{D}}^{2}$ dependence over the gatedrain spacing of InAlGaN/GaN MIS-HEMTs by considering two noise sources in the channel: channel noise under the gate and channel noise in the gate-drain access regions [27].

Here, the source and drain contact resistances and the gatesource access region resistance are negligible, hence the noise sources of these resistances are not considered in the model. Following the procedure of [27], the experimental data representing the relative drain current channel noise under the gate $\left(\mathrm{S}_{\mathrm{IRCH}} / \mathrm{I}_{\mathrm{D}}{ }^{2}\right)$ versus gate overdrive voltage $\left(\mathrm{V}_{\mathrm{GS}}-\mathrm{V}_{\mathrm{TH}}\right)$, in the linear regime $\left(\mathrm{V}_{\mathrm{DS}}=200 \mathrm{mV}\right)$, of InAlGaN/GaN HEMTs with $\mathrm{L}_{\mathrm{GD}}=1,2$ and $3 \mu \mathrm{m}$ are shown in Fig.5. The relative drain current channel noise under the gate $\mathrm{S}_{\mathrm{IRCH}} / \mathrm{I}_{\mathrm{D}}{ }^{2}$ decreases with the gate overdrive as $\left(\mathrm{V}_{\mathrm{GS}}-\mathrm{V}_{\mathrm{TH}}\right)^{-3}$ with no significant impact of $\mathrm{L}_{\mathrm{GD}}$. Similar dependence over $\mathrm{V}_{\mathrm{GS}}-\mathrm{V}_{\mathrm{TH}}$ indicating the dominant channel noise is located under the gate, as reported in previous works [25,26]. In [27], the channel noise under the gate was also the main contribution of the total channel noise for for low gate-drain access region spacing $\mathrm{L}_{\mathrm{GD}}$ $<10 \mu \mathrm{m}$.

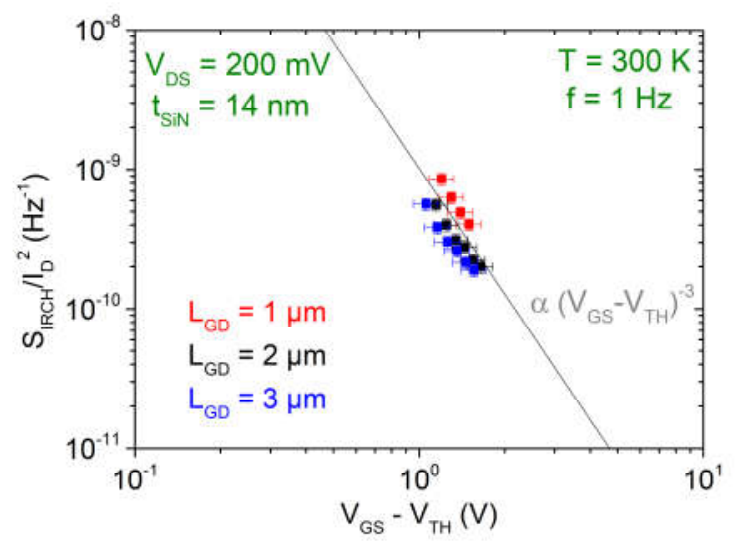

Fig. 5. Dependence of the relative drain current channel noise under the gate $\mathrm{S}_{\mathrm{IRCH}} / \mathrm{I}_{\mathrm{D}}{ }^{2}$ on the gate overdrive $\left(\mathrm{V}_{\mathrm{GS}}-\mathrm{V}_{\mathrm{TH}}\right)$ at $\mathrm{f}=1 \mathrm{~Hz}, \mathrm{~V}_{\mathrm{DS}}=200 \mathrm{mV}$ and $\mathrm{T}=300 \mathrm{~K}$.

\section{CONCLUSION}

The low frequency noise of sub-10 nm quaternary barrier layer InAlGaN/GaN HEMTs with two different MOVPE in situ $\mathrm{SiN}$ passivation thicknesses and ultra-short gate was studied. The low frequency noise is not impacted by the in situ SiN thickness and shows a high InAlGaN/GaN interface quality. The $\mathrm{S}_{\mathrm{ID}} / \mathrm{I}_{\mathrm{D}}{ }^{2}$ dependence over $\mathrm{V}_{\mathrm{GS}}-\mathrm{V}_{\mathrm{TH}}$ indicates that the dominant channel noise is located under the gate. Sub-10 $\mathrm{nm}$ InAlGaN quaternary barrier combined with in situ $\mathrm{SiN}$ passivation layer are promising to enhance the performance of GaN based HEMTs.

\section{REFERENCES}

[1] F. Medjdoub, R. Kabouche, A. Linge, B. Grimbert, M. Zegaoui, P. Gamarra, C. Lacam, M. Tordjman and M-A di Forte-Poisson "High electron mobility in high polarization sub-10 nm barrier thickness InAlGaN/GaN heterostructure,", Appl. Phys. Express, 8, 101001, 2015, 10.7567/APEX.8.101001.

[2] N. Ketteniss, L.R. Khoshroo, M. Eickelkamp, M. Heuken, H. Kalisch, R. H. Jansen and A. Vescan "Study on quaternary AlInGaN/GaN HFETs grown on sapphire substrates," Semicond. Sci. Technol., 25, 075013, 2010, 10.1088/0268-1242/25/7/075013.

[3] R. Wang, G. Li, G. Karbasian, J. Guo, B. Song, Y. Yue, Z. Hu, O. Laboutin, Y. Cao, W. Johnson, G. Snider, P. Fay, D. Jena, and H. G. Xing "Quaternary Barrier InAlGaN HEMTs With fT / fmax of 230/300 GHz," IEEE Electron Device Lett., vol. 34, no. 3, Mar 2013, 10.1109/LED.2013.2238503.

[4] E. Dogmus, R. Kabouche, S. Lepilliet, A. Linge, M. Zegaoui, H. BenAmmar, M-P. Chauvat, P. Ruterana, P. Gamarra, C. Lacam, M. Tordjman and F. Medjdoub, "InAlGaN/GaN HEMTs at cryogenic temperatures," Electronics, 5, 31, 2016, 10.3390/electronics5020031.

[5] Y. Niida, Y. Kamada, T. Ohki, S. Ozaki, K. Makiyama, Y. Minoura, N. Okamoto, M. Sato, K. Joshin, and K. Watanabe "3.6 W/mm High Power Density W-band InAlGaN/GaN HEMT MMIC Power Amplifier," IEEE Topical Conference on Power Amplifiers for Wireless and Radio Applications (PAWR), 24-27 Jan. 2016, 10.1109/PAWR.2016.7440153.

[6] R. Aubry, J. C. Jacquet, M. Oualli, O. Patard, S. Piotrowicz, E. Chartier, N. Michel, L. Trinh Xuan, D. Lancereau, C. Potier, M. Magis, P. Gamarra, C. Lacam, M. Tordjman, O. Jardel, C. Dua, and S. L. Delage "ICP-CVD SiN Passivation for High-Power RF InAlGaN/GaN/SiC HEMT," IEEE Electron Device Lett., vol. 37, no. 5, May 2016, 10.1109/LED.2016.2540164.

[7] G. Meneghesso, G. Verzellesi, F. Danesin, F. Rampazzo, F. Zanon, A. Tazzoli, M. Meneghini, and E. Zanoni, "Reliability of GaN HighElectron-Mobility Transistors: State of the Art and Perspectives," IEEE Trans. Device Mater. Rel., 8, 2, 332, 2008, 10.1109/TDMR.2008.923743.

[8] J.A. del Alamo, J. Joh "GaN HEMT reliability," Microelectron. Reliab., 49, 1200-1206, 2009, 10.1016/j.microrel.2009.07.003.

[9] D. Marcon, J. Viaene, P. Favia, H. Bender, X. Kang, S. Lenci, S. Stoffels, and S. Decoutere, "Reliability of AlGaN/GaN HEMTs: Permanent leakage current increase and output current drop," Microelectron. Reliab., vol. 52, nos. 9-10, pp. 2188-2193, 2012, 10.1016/j.microrel.2012.06.052.

[10] B. M. Green, K. K. Chu, E. M. Chumbes, J. A. Smart, J. R. Shealy, and L. F. Eastman, "The Effect of Surface Passivation on the Microwave Characteristics of Undoped AlGaN/GaN HEMT's," IEEE Electron Device Lett., 21, 6, 2000, 10.1109/55.843146.

[11] R. Vetury, N. Q. Zhang, S. Keller, and U. K. Mishra, "The Impact of Surface States on the DC and RF Characteristics of AlGaN/GaN HFETs," IEEE Trans. Electron Devices, 48, 3, 2001, $10.1109 / 16.906451$.

[12] S. Arulkumaran, T. Egawa, H. Ishikawa, and T. Jimbo "Surface passivation effects on $\mathrm{AlGaN} / \mathrm{GaN}$ high-electron-mobility transistors with $\mathrm{SiO}_{2}, \mathrm{Si}_{3} \mathrm{~N}_{4}$, and silicon oxynitride," Appl. Phys. Lett., Vol. 84, No. 4, 26 January 2004, 10.1063/1.1642276.

[13] J. Derluyn, S. Boeykens, K. Cheng, R. Vandersmissen, J. Das, W. Ruythooren, S. Degroote, M.R. Leys, M. Germain, and G. Borghs, "Improvement of $\mathrm{AlGaN} / \mathrm{GaN}$ high electron mobility transistor structures by in situ deposition of a $\mathrm{Si}_{3} \mathrm{~N}_{4}$ surface layer," J. Appl. Phys., vol. 98 , no. 5 , p. $054501,2005,10.1063 / 1.2008388$.

[14] G.R. Mutta, J.M. Routoure, B. Guillet, L. Méchin, J. Grandal, S. MartinHorcajo, T. Brazzini, F. Calle, M.A. Sánchez-García, P. Marie and P. Ruterana, "Volume charge carrier number fluctuations probed by low 
frequency noise measurements in InN layers", Appl. Phys. Lett., vol. 98, no. 25 , p. $252104,2011,10.1063 / 1.3601855$.

[15] M. Silvestri, M. J. Uren, N. Killat, D. Marcon, and M. Kuball, "Localization of off-stress-induced damage in $\mathrm{AlGaN} / \mathrm{GaN}$ high electron mobility transistors by means of low frequency $1 / \mathrm{f}$ noise measurements", Appl. Phys. Lett., 103, 043506, 2013 , 10.1063/1.4816424;

[16] M. Rzin, A. Curutchet, N. Labat, N. Malbert, L. Brunel, and B. Lambert, "Schottky gate of AlGaN/GaN HEMTs: Investigation with DC and low frequency noise measurements after 7000 hours HTOL test", in Proc. Int. Conf. Noise Fluctuations (ICNF), Xi'an, China, Jun. 2015, pp. 1-4, 10.1109/ICNF.2015.7288607.

[17] H. Rao and G. Bosman, "Device reliability study of high gate electric field effects in $\mathrm{AlGaN} / \mathrm{GaN}$ high electron mobility transistors using low frequency noise spectroscopy", J. Appl. Phys., vol. 108, no. 5, p. 053707, 2010, 10.1063/1.3475991.

[18] J. H. Seo, Y. J. Yoon, D.-H. Son, J.-G Kim, J.-H. Lee, J.-H. Lee, K-S. Im and I. M Kang, "A novel analysis of $\mathrm{L}_{\mathrm{gd}}$ dependent- $1 / \mathrm{f}$ noise in $\mathrm{In}_{0.08} \mathrm{Al}_{0.92} \mathrm{~N} / \mathrm{GaN}$ fin-HEMTs," IEEE Electron Device Lett., vol. 39, pp. 1552-1555, 2018, 10.1109/LED.2018.2865564

[19] A. V. Vertiatchikh and L. F. Eastman, "Effect of the surface and barrier defects on the AlGaN/GaN HEMT low-frequency noise performance," IEEE Electron Device Lett., vol. 24, no. 9, pp. 535-537, Sep. 2003, 10.1109/LED.2003.816588.

[20] C.M. Jeon and J.L. Lee, "Effects of tensile stress induced by silicon nitride passivation on electrical characteristics of $\mathrm{AlGaN} / \mathrm{GaN}$ heterostructure field-effect transistors", Appl. Phys. Lett., 86, 172101, $2005,10.1063 / 1.1906328$.

[21] H. Jiang, C. Liu, Y. Chen, X. Lu, C. W. Tang, and K. M. Lau "Investigation of In Situ SiN as Gate Dielectric and Surface Passivation for GaN MISHEMTs", IEEE Trans. Electron Devices, Vol. 64, No. 3, 832, 2017, 10.1109/TED.2016.2638855.

[22] T. Huang, O. Axelsson, T. N. T. Do, M. Thorsell, , D. Kuylenstierna, and N. Rorsman, "Influence on Noise Performance of GaN HEMTs With In Situ and Low-Pressure-Chemical-Vapor-Deposition $\mathrm{SiN}_{\mathrm{x}}$ Passivation", IEEE Trans. Electron Devices, Vol. 63, No. 10, 2016 , 10.1109/TED.2016.2597758

[23] P. Moens, C. Liu, A. Banerjee, P. Vanmeerbeek, P. Coppens, H. Ziad, A. Constant, Z. Li, H. De Vleeschouwer, J. RoigGuitart, P. Gassot, F. Bauwens, E. De Backer, B. Padmanabhan, A. Salih, J. Parsey and M. Tack, "An Industrial Process for 650V rated GaN-on-Si Power Devices using in-situ SiN as a Gate Dielectric", in Proc. of the 26th International Symposium on Power Semiconductor Devices \& IC's (ISPSD) Jun 2014 Waikoloa, Hawaii, pp. 374-377.

[24] P. Gamarra, C. Lacam, M. Tordjman, F. Medjdoub, M-A di FortePoisson "In-situ passivation of quaternary barrier InAlGaN/GaN HEMTs", J. Cryst. Growth, 464, 143, 2017 10.1016/j.jcrysgro.2016.11.014.

[25] J. M. Peransin, P. Vignaud, D. Rigaud, and L.K.J. Vandamme, "1/f noise in MODFET's at low drain bias", IEEE Trans. Electron Devices, Vol 37, No. 10, pp. 2250-2253, 1990, 10.1109/16.59916.

[26] H. Rao, G. Bosman, "Simultaneous low-frequency noise characterization of gate and drain currents in $\mathrm{AlGaN} / \mathrm{GaN}$ high electron mobility transistors", J. Appl. Phys., vol. 106, pp. 103712, 2009, 10.1063/1.3259437.

[27] M. Rzin, J-M. Routoure, B. Guillet, L. Méchin, C. Lacam, M. Morales, P. Gamarra, P. Ruterana and F. Medjdoub "Impact of gate-drain spacing on low frequency noise performance of in-situ SiN passivated InAlGaN/GaN MIS-HEMTs", IEEE Trans. Electron Devices, 64, 7, 2820, 2017, 10.1109/TED.2017.2703809. 